\title{
Effects of a Persistent Sodium Current Through Mutated hNav1.5 Sodium Channels on Intracellular Ionic Homeostasis in a Ventricular Cell Model
}

\author{
G Christe ${ }^{1}$, L Restier ${ }^{2}$, M Chahine ${ }^{3}$, P Chevalier $^{2}$, M Pasek $^{4}$ \\ ${ }^{1}$ INSERM E0219, CEA Grenoble, Grenoble, France \\ ${ }^{2}$ Hôpital Cardiologique, Lyon, France \\ ${ }^{3}$ Hôpital Laval, Sainte-Foy, Quebec, Canada \\ ${ }^{4}$ Institute of Thermomechanics, Czech Academy of Sciences, Brno, Czech Republic
}

\begin{abstract}
In LQT3 patients, SCN5A mutations were found that lead to a small fraction of persistent hNav1.5 current. We explored the effects of such a change on the intracellular ionic homeostasis in a model of guinea-pig cardiac ventricular cell. At steady-state under $1 \mathrm{~Hz}$ stimulation, the presence of a persistent $\mathrm{Na}^{+}$current $\left(I_{\text {Nap }}\right)$ with $g_{\text {Nap }}$ $0.02 \mathrm{~ms} / \mathrm{cm}^{2}$ led to a prolongation of the action potential from $153 \mathrm{~ms}$ (control) to $223 \mathrm{~ms}$ and an increase of $\left[\mathrm{Na}^{+}\right]_{i}$, diastolic and systolic $\left[\mathrm{Ca}^{2+}\right]_{i}$ and $\left[\mathrm{Ca}^{2+}\right]_{\text {SRup }}$ by $10 \%, 30 \%, 40 \%$ and $43 \%$, respectively. These changes were larger at $3 \mathrm{~Hz}$. Such intracellular $\mathrm{Na}^{+}$and $\mathrm{Ca}^{2+}$ overload was not found when the action potential prolongation (to $222 \mathrm{~ms}$ at $1 \mathrm{~Hz}$ ) was due to decreased $I_{K r}$ and $I_{K s}$ currents. The model with $I_{\text {Nap }}$ became arrhythmogenic when $\left[\mathrm{K}^{+}\right]_{e}$ was lowered from 5.4 to 5.0 $m M$, whereas control and low $K^{+}$current models did not produce arrhythmias even when $\left[\mathrm{K}^{+}\right]_{e}$ was $2.5 \mathrm{mM}$.
\end{abstract}

\section{Introduction}

Mechanisms by which mutation-induced alterations of the hNav1.5 current predispose LQT3 patients to arrhythmias have been explored from an electrical point of view [1-3]. However, a possible contribution of altered ionic homeostasis was not explored quantitatively. In particular, the presence of a persistent $\mathrm{Na}^{+}$current $\left(\mathrm{I}_{\mathrm{Nap}}\right)$ during the action potential might cause elevation of intracellular $\left[\mathrm{Na}^{+}\right]$, a condition that predisposes to calcium overload and arrhythmogenesis. We explored whether this effect would be quantitatively important in a computer model of guinea pig ventricular myocyte. Two modifications of the model causing equivalent prolongation of the action potential were compared. In the first modified model, a persistent $\mathrm{Na}^{+}$current was introduced, to mimic a mutation-induced LQT3 condition. In the other modification, a decrease in $\mathrm{I}_{\mathrm{Kr}}$ and $\mathrm{I}_{\mathrm{Ks}}$ currents was introduced to cause a similar prolongation of the action potential. The two models were compared in their ability to cause changes in intracellular ionic homeostasis. We further evaluated the response of these modified models to an increase in heart rate that favors $\mathrm{Ca}^{2+}$ overload and to hypokalaemia, that may trigger arrhythmias in LQT patients.

\section{Methods}

A ventricular cell model that includes ionic currents, intracellular ionic homeostasis and a single compartment tubular system [4] was modified to closely match the properties of guinea-pig ventricular cells at $37^{\circ} \mathrm{C}$ (briefly described in [5] - this volume). This model was written and integrated under the MATLAB environment.

In the control version of the model (named Cont), $\mathrm{I}_{\mathrm{Nap}}$ was not present and both the fast and slow outwardly rectifying potassium currents $\left(\mathrm{I}_{\mathrm{Kr}}\right.$ and $\left.\mathrm{I}_{\mathrm{Ks}}\right)$ were formulated with a maximal conductance of $0.8 \mathrm{mS} / \mathrm{cm}^{2}$ (which is for $\left[\mathrm{K}^{+}\right]_{\mathrm{e}}=5.4 \mathrm{mM}$ for $\mathrm{I}_{\mathrm{Kr}}$ and for $\left[\mathrm{Ca}^{2+}\right]_{\mathrm{i}}=32.5$ $\mathrm{nM}$ for $\mathrm{I}_{\mathrm{Ks}}$ ).

In the first modification of the model (named $+I_{N a p}$ ), a persistent $\mathrm{Na}^{+}$current was introduced in the form:

$I_{\mathrm{Nap}}=g_{\mathrm{Nap}} k_{\mathrm{Nap}}\left(V_{\mathrm{m}}-E_{\mathrm{Nap}}\right)$

with $\quad k_{\mathrm{Nap}}=\frac{1}{1+e^{-\left(V_{\mathrm{m}}+54\right) / 8}}$

and $E_{\text {Nap }}=\frac{R T}{F} \frac{\left[\mathrm{Na}^{+}\right]_{\mathrm{e}}+0.12\left[\mathrm{~K}^{+}\right]_{\mathrm{e}}}{\left[\mathrm{Na}^{+}\right]_{\mathrm{i}}+0.12\left[\mathrm{~K}^{+}\right]_{\mathrm{i}}}$.

The maximal conductance $g_{\text {Nap }}$ was set to 0.02 $\mathrm{mS} / \mathrm{cm}^{2}$.

In a second modification (named $-I K$ ) of model Cont, the maximal conductance for both $\mathrm{I}_{\mathrm{Kr}}$ and $\mathrm{I}_{\mathrm{Ks}}$ was reduced by $67 \%$ the same value of $0.25 \mathrm{mS} / \mathrm{cm}^{2}$. Both modified models and the control model were run for at least $600 \mathrm{~s}$ cell life time to ensure that all variables had reached steady-state. For examination of susceptibility of each model to generate arrhythmias in lowered extracellular 
$\left[\mathrm{K}^{+}\right]_{\mathrm{e}}$, each model was run for $300 \mathrm{~s}$ in each condition.

\section{Results}

Fig. 1, left column shows the time-course of changes in several variables during one cycle at $1 \mathrm{~Hz}$ stimulation frequency once the model reached dynamic stability.
Intracellular $\mathrm{Na}^{+}$concentration $\left(\left[\mathrm{Na}^{+}\right]_{\mathrm{i}}, 10.95 \mathrm{mM}\right.$ in Cont model - fig. 1c) increased to $12.1 \mathrm{mM}(+10.5 \%)$ in the $+I N a_{p}$ model whereas it decreased to $9.95 \mathrm{mM}(-9.1 \%)$ in the $-I K$ model. In the $+I N a_{p}$ model, the intracellular $\mathrm{Ca}^{2+}$ concentration $\left(\left[\mathrm{Ca}^{2+}\right]_{i}\right.$, fig. 1d) was larger than in Cont model in both its peak value $(1.08 \mu \mathrm{M}$ vs $0.77 \mu \mathrm{M}$
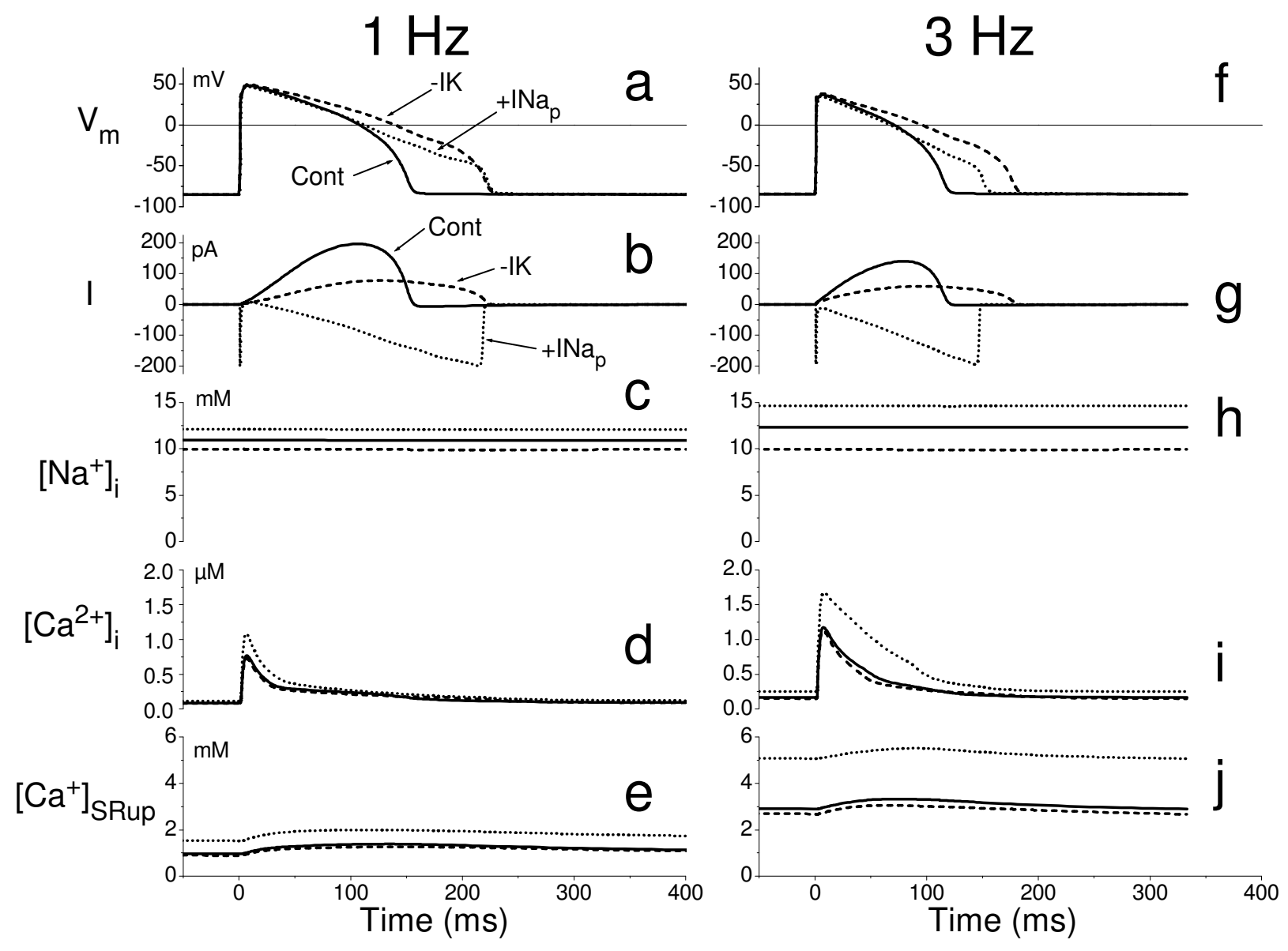

Figure 1. Ouput data from models Cont,$+I N a_{p}$ and $-I K$ after $600 \mathrm{~s}$ of regular stimulation at $1 \mathrm{~Hz}$ (left column) or at $3 \mathrm{~Hz}$ (right column) in the I-clamp mode. Continuous lines refer to the Cont model, dotted lines to the $+I N a_{p}$ model and dashed lines to the $-I K$ model.

The action potential duration at $90 \%$ repolarization $\left(\mathrm{APD}_{90}\right.$ ) was similar in both modified models (i.e. $223 \mathrm{~ms}$ for model $+I N a_{p}$ and $222 \mathrm{~ms}$ for model $-I K$ ). This represented a $46 \%$ prolongation of $\mathrm{APD}_{90}$ versus $153 \mathrm{~ms}$ in the Cont model (fig. 1a).

Fig. $1 \mathrm{~b}$ shows the magnitudes of the sum of $\mathrm{I}_{\mathrm{Kr}}$ and $\mathrm{I}_{\mathrm{Ks}}$ (in Cont and $-I K$ models) and of $\mathrm{I}_{\mathrm{Nap}}$ in $+I N a_{p}$ model. in Cont model i.e. $+40 \%)$ and in its end-diastolic value $(0.11 \mu \mathrm{M}$ vs $0.09 \mu \mathrm{M}$ in Cont model i.e. $+30 \%)$. In the $-I K$ model, these values were slightly lowered to respectively $0.73 \mu \mathrm{M}(-5 \%)$ and $0.08 \mu \mathrm{M}(-8 \%)$. Correspondingly, the $\mathrm{Ca}^{2+}$ concentration in the uptake compartment of the SR ([C $\left.{ }^{2+}\right]_{\text {SRup }}$, fig. 1e) in $+I N a_{p}$ model was higher than in Cont model by $58 \%$ at peak and $43 \%$ at the end of diastole whereas in the $-I K$ model, these values were, respectively, $10 \%$ and $7 \%$ lower than in Cont model.

Thus at a stimulation rate of $1 \mathrm{~Hz}$, the presence of a persistent $\mathrm{Na}^{+}$current caused increase $\left[\mathrm{Na}^{+}\right]_{\mathrm{i}}$ and $\left[\mathrm{Ca}^{2+}\right]_{\mathrm{i}}$, whereas the model with decreased $\mathrm{K}^{+}$currents, although 
producing similar lengthening of action potential duration, caused a slight decrease. Next, we tested the response of these models to a high stimulation rate $(3 \mathrm{~Hz}$, fig. 1 right column). The action potential remained prolonged versus control in both modified models (fig. 1f), but this was less for the $+I N a_{p}$ model (+30\%) than for the $-I K$ model $(+53 \%)$. The time course of modified currents is reported in fig. $1 \mathrm{~g}$. For both modified models, the deviations of $\left[\mathrm{Na}^{+}\right]_{\mathrm{i}}$ (fig. $1 \mathrm{~h}$ ), $\left[\mathrm{Ca}^{2+}\right]_{\mathrm{i}}$ (fig. 1i) and $\left[\mathrm{Ca}^{2+}\right]_{\text {SRup }}$ (fig. $1 \mathrm{j}$ ) from levels in the Cont model were all amplified by the higher stimulation frequency versus those at $1 \mathrm{~Hz}$. The model with persistent $\mathrm{Na}^{+}$current thus showed a tendency to overload the cell with $\mathrm{Na}^{+}$and $\mathrm{Ca}^{2+}$ that is enhanced at higher rates of stimulation.
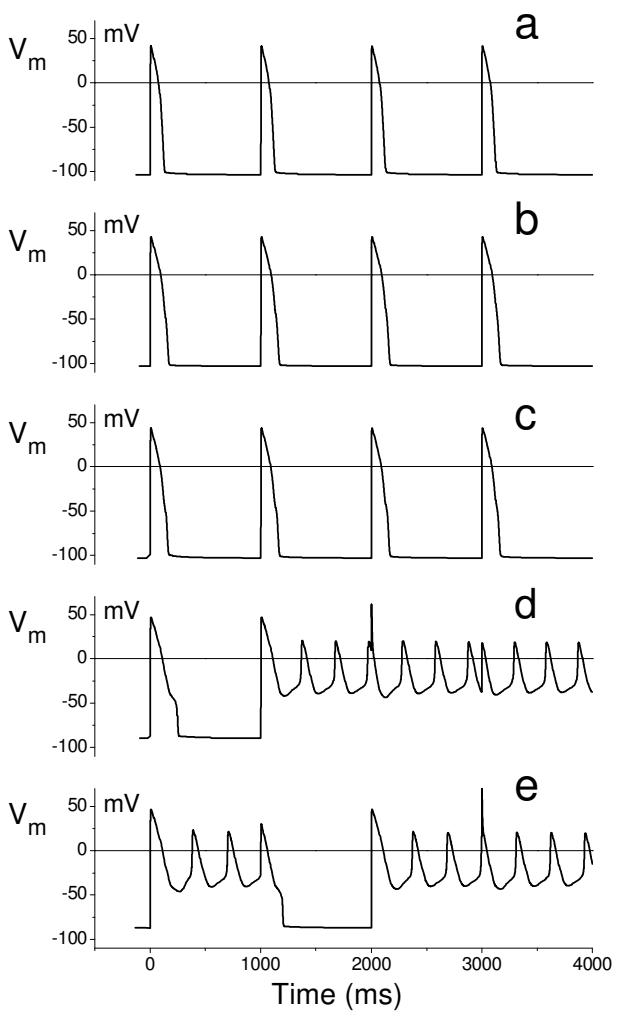

Figure 2. Action potentials in low $\left[\mathrm{K}^{+}\right]_{\mathrm{e}}$ at $1 \mathrm{~Hz}$ stimulation frequency. a: the Cont model after $300 \mathrm{~s}$ in $2.5 \mathrm{mM}\left[\mathrm{K}^{+}\right]_{\mathrm{e}}$. b: the $-I K$ model after $300 \mathrm{~s}$ in $2.5 \mathrm{mM}$ $\left[\mathrm{K}^{+}\right]_{\mathrm{e}}$. c: the $+I N a_{p}$ model with $g N a_{p}=0.01 \mathrm{mS} / \mathrm{cm}^{2}$ after $300 \mathrm{~s}$ in $2.5 \mathrm{mM}\left[\mathrm{K}^{+}\right]_{\mathrm{e}}$. d: the $+I N a_{p}$ model with $g N a_{p}=0.018 \mathrm{mS} / \mathrm{cm}^{2}$ during the first $4 \mathrm{~s}$ of simulation in $4.5 \mathrm{mM}\left[\mathrm{K}^{+}\right]_{\mathrm{e}}$, , after $300 \mathrm{~s}$ regular activity in $5.0 \mathrm{mM}$ $\left[\mathrm{K}^{+}\right]_{\mathrm{e}}$ (not shown). e: the +INap model with $g N a_{p}=0.02$ $\mathrm{mS} / \mathrm{cm}^{2}$ during the first $4 \mathrm{~s}$ of simulation at $5.0 \mathrm{mM}\left[\mathrm{K}^{+}\right]_{\mathrm{e}}$.
Hypokalaemia is a condition reported to trigger arrhythmias in LQT3 patients. We tested the response of each model to gradual lowering of external $\mathrm{K}^{+}$ concentration $\left(\left[\mathrm{K}^{+}\right]_{\mathrm{e}}\right)$ from the control value of $5.4 \mathrm{mM}$. The results are summarized in fig. 2. The Cont model could stand lowering of $\left[\mathrm{K}^{+}\right]_{\mathrm{e}}$ to $2.5 \mathrm{mM}$ (fig. $2 \mathrm{a}$ ) as well as the $-I K$ model (fig. 2b). Model $+I N a_{p}$ displayed arrhythmic behavior at $5 \mathrm{mM}$ (fig. 2e). Then, intermediate values of the maximal conductance for $\mathrm{I}_{\mathrm{Nap}}$ were used in the $+I N a_{p}$ model and the model run for $600 \mathrm{~s}$ in normal $\left[\mathrm{K}^{+}\right]_{\mathrm{e}}$. After that the simulations with gradually lowered $\left[\mathrm{K}^{+}\right]_{\mathrm{e}}$ were run again. The results showed that when $g_{\mathrm{Nap}}$ was lowered to $0.018 \mathrm{mS} / \mathrm{cm}^{2}$, the model became arrhythmic at $4.5 \mathrm{mM}$ (fig. 2d) whereas when $g_{\text {Nap }}$ was lowered to $0.01 \mathrm{mS} / \mathrm{cm}^{2}$, the model could stand $\left[\mathrm{K}^{+}\right]_{\mathrm{e}}$ as low as $2.5 \mathrm{mM}$ and keep regular beating (fig. 2c).

\section{Discussion and conclusions}

The magnitude of the persistent current that was introduced in the $+I N a_{p}$ model caused an action potential prolongation by $46 \%$, which is in the range reported for the QTc lengthening in LQT3 syndrome. For so doing, $\mathrm{g}_{\text {Nap }}$ was set to a value of $0.02 \mathrm{mS} / \mathrm{cm} 2$ which represents $0.066 \%$ of the maximal conductance for the fast $\mathrm{Na}^{+}$ current $\left(\mathrm{I}_{\mathrm{Na}}\right)$. The magnitude of the persistent current for exogenously expressed mutated hNav1.5 channels amounted 1 to $6 \%$ of the peak $\mathrm{Na}^{+}$current [6,7]. Thus only a small part of fast $\mathrm{Na}^{+}$channels $(1.1 \%$ to $6.6 \%)$ would need to be mutated to account for the fraction of $0.066 \%$ persistent $\mathrm{Na}^{+}$current. This is consistent with the heterozygous presence of such mutations, allowing a mixed population of mutated and wild-type channels to coexist in cardiac cells of patients bearing such mutations. It also entails that the mutated channel genes need not attain a high level of expression for causing a LQT3 phenotype.

Here we obtained indication that the presence of a persistent $\mathrm{Na}^{+}$current causes intracellular overload in $\mathrm{Na}^{+}$ and $\mathrm{Ca}^{2+}$. In contrast, a opposite change in $\mathrm{Na}^{+}$and $\mathrm{Ca}^{2+}$ load was seen when a similar action potential prolongation was caused by a $68 \%$ decrease in $\mathrm{K}^{+}$ currents $\mathrm{I}_{\mathrm{Kr}}$ and $\mathrm{I}_{\mathrm{Ks}}$. This suggests that the proarrhythmogenic background created by these two alterations in ionic currents is different, and that LQT3 with persistent $\mathrm{Na}^{+}$current makes the cell more sensitive to an aggravation of $\mathrm{Na}^{+}$and $\mathrm{Ca}^{2+}$ overload. This is supported by the arrhythmogenicity of $\left[\mathrm{K}^{+}\right]_{\mathrm{e}}$ lowering in the $+I N a_{p}$ model that was not seen in the $-I K$ model. However, when $\mathrm{g}_{\mathrm{Nap}}$ was halved in the $+I N a_{p}$ model, it became resistant even to a low $\left[\mathrm{K}^{+}\right]_{\mathrm{e}}$ of $2.5 \mathrm{mM}$, as Cont and $-I K$ models. Thus there is a threshold magnitude of $\mathrm{I}_{\mathrm{Nap}}$ below which the higher sensitivity to low $\left[\mathrm{K}^{+}\right]_{\mathrm{e}}$ did not appear.

It may be noted that the change introduced in our 
model to account for a persistent $\mathrm{Na}^{+}$current is not an exact image of the change induced in the fast hNav1.5 current by mutations causing LQT3 phenotype [1,6,7]. In particular, the voltage shifts of the steady-state inactivation versus voltage relation and the accelerated fast inactivation of the hNav1.5 current were not taken into account here. This was purposely done to explore the effects of a persistent $\mathrm{Na}^{+}$current per se on ionic homeostasis. Nevertheless, the complete set of changes for a given mutation should be explored to test whether the effects outlined here are altered. Another simplification is that the equations used here for the persistent $\mathrm{Na}^{+}$current do not account for the ultra-slow inactivation present in the persistent current of mutated channels $[1,6,7]$. However, as the time constant of this inactivation was several fold longer than the duration of action potentials in the present model, the magnitude of the persistent $\mathrm{Na}^{+}$current should be negligibly altered within the duration of an action potential.

The possible effects of the presence of the transverse axial tubular system (TATS) in our model were not explored here. We have shown in a former study that the TATS exerts a protective effect in retarding the proarrhythmic effect of progressive hypokalaemia [8]. Such an effect should not alter the conclusions from the present work.

These results were obtained in a model of guinea-pig ventricular cell and may not readily hold for a human cardiac cell. However, they suggest to consider the possibility that intracellular $\mathrm{Na}^{+}$and $\mathrm{Ca}^{2+}$ overload may contribute to predisposition of LQT3 patients to syncope.

\section{Acknowledgements}

This work was supported by a grant to GC from the Fédération des Maladies Orphelines, Paris and by the project AV0Z 20760514 from the Institute of Thermomechanics of Czech Academy of Sciences.

\section{References}

[1] Bennett PB, Yazawa K, Makita N, George AL, Jr. Molecular mechanism for an inherited cardiac arrhythmia. Nature 1995;376:683-685.

[2] Clancy CE, Rudy Y. $\mathrm{Na}^{+}$channel mutation that causes both Brugada and long-QT syndrome phenotypes: a simulation study of mechanism. Circulation 2002;105:1208-1213.

[3] Clancy CE, Tateyama M, Liu H, Wehrens XH, Kass RS. Non-equilibrium gating in cardiac $\mathrm{Na}+$ channels: an original mechanism of arrhythmia. Circulation 2003; 107:2233-2237.

[4] Pasek M, Christé G, Simurda J. A quantitative model of cardiac ventricular cell incorporating the transverse-axial tubular system. Gen Physiol Biophys 2003;22:355-368.

[5] Pasek M, Simurda J, Orchard CH, Christe G. Physiological role of transverse-axial tubular system in cardiac ventricular myocytes: a simulation study. Computers in Cardiology 2005;(Abstract), this volume.

[6] Chang CC, Acharfi S, Wu MH, Chiang FT, Wang JK, Sung TC, Chahine M. A novel SCN5A mutation manifests as a malignant form of long QT syndrome with perinatal onset of tachycardia/bradycardia. Cardiovasc Res 2004;64:268-278.

[7] Baroudi G, Chahine M. Biophysical phenotypes of SCN5A mutations causing long QT and Brugada syndromes. FEBS Letters 2000;487:224-228.

[8] Pasek M, Christé G, Simurda J. Arrhythmogenic effect of extracellular $\mathrm{K}^{+}$-depletion is prevented by the transverseaxial tubular system in a ventricular cardiac cell model. Scripta Medica 2002;75:179-186.

Address for correspondence

Georges Christé, Present address: UMR5123,

Univ. Claude Bernard - Lyon1,

F 69622 Villeurbanne Cedex, France

E-mail address: christe@1yon.inserm.fr 